\title{
Frontal Lobe and Kindling in the Rat
}

\author{
MICHAEL E. CORCORAN, HARALD URSTAD, JAMES A. McCAUGHRAN JR., AND JUHN A. WADA
}

SUMMARY: To test the hypothesis that the cortex participates in amygdaloid kindling in rats, bilateral aspiration lesions were made in various cortical areas in rats prior to kindling. Lesions in orbital cortex (on the dorsal lip of the rhinal sulcus) or prefrontal cortex (area 10) significantly retarded the rate of amygdaloid kindling; lesions in motor cortex, anterior cingulate cortex, or visual cortex were without effect. Detailed analysis indicated that the orbital lesioned and frontal-lesioned rats kin-

RÉSUMÉ: Des lésions bilatérales par aspiration furent faites dans plusieurs sites corticaux chez le rat préalablement à des expériences de "kindling". Ces résultats indiquent que le lobe frontal participe dans l'élaboration et la généralisation des convulsions amyg- dled relatively normally up to the second-last stage of amygdaloid kindling, in which stage they perseverated significantly longer than the controls and the other lesioned rats.

These results suggest that areas of the frontal lobe participate in the elaboration and generalization of amygdaloid seizures in rats. Although retarded in rate, kindling nonetheless occurred in the lesioned rats, indicating that these cortical areas are not essential for the development of amygdaloid seizures.

daliennes chez le rat. Malgré un certain ralentissement du rythme, le "kindling", est néanmoins apparu chez les rats lésionnés, indiquant donc que ces régions corticales ne sont pas absolument essentielles pour le développement des convulsions amygdaliennes.
From the Division of Neurological Sciences, University of British Columbia, Vancouver, British Columbia.

Reprint requests to Dr. M. E. Corcoran, Division of Neurological Sciences, University of British Columbia, 2075 Wesbrook Place, Vancouver V6T IW5 Canada.

Supported by a Killam Postdoctoral Research Scholarship of the Canada Council awarded to M. E. Corcoran, by a grant from the Medical Research Council of Canada awarded to J. A. Wada and M. E. Corcoran, and by grants from the U.S. National Institutes of Health awarded to J. A. Wada. We thank Jane Rothwell Corcoran for preparing some of the figures, and Douglas Chidgey for excellent technical assistance.
As a first step in investigating the morphological, biochemical, or neurophysiological changes that accompany amygdaloid kindling, it seems logical to attempt to localize those areas of the brain that actively and perhaps critically participate in kindling. A number of reports have suggested that the mesencephalic reticular formation and related structures in the midbrain and lower brainstem may play a prominent role in amygdaloid kindling (McCaughran, Corcoran, and Wada, 1975; McIntyre, 1975; Wada and Sato, $1974,1975)$. So may the frontal cortex, as suggested by Tanaka (1972). He found that rhythmic sharp waves developed in the frontal cortex (presumably including motor cortex) coincident with the evolution of clinical motor manifestations provoked by amygdaloid stimulation in rabbits. As kindling progressed the cortical epileptiform activity became independent of amygdaloid afterdischarge, and Tanaka concluded that the participation of the motor cortex is indispensible for the expression of kindled amygdaloid seizures.

The present report describes our own efforts to examine the role of anterior cortical areas in amygdaloid kindling. The first experiment describes electrophysiological evidence that implicates motor cortex in the intermediate and later stages of amygdaloid kindling in rats, in confirmation of Tanaka's (1972) findings. In the second experiment we attempted to extend this finding by examining the effects upon amygdaloid kindling of ablation of the motor cortex and other areas of cortex.

\section{EXPERIMENT 1: METHODS}

Subjects and surgery.

Eight male hooded rats of the Royal Victoria Hospital strain were 
used. The rats weighed $250-300 \mathrm{~g}$ at the time of surgery, and were housed individually with free access to food and water. They carried bipolar depth electrodes implanted bilaterally into the amygdala (AM) with conventional stereotaxic procedures. The depth electrodes consisted of twisted nichrome wire 127 $\mu \mathrm{m}$ in diameter, with a tip separation of $0.5 \mathrm{~mm}$. Bipolar cortical electrodes were also implanted bilaterally over the motor cortex in each rat. The cortical electrodes were constructed of 2 miniature stainless steel screws with flat tips; the anterior screw rested over cortical area 6 (as indicated in the cortical maps in

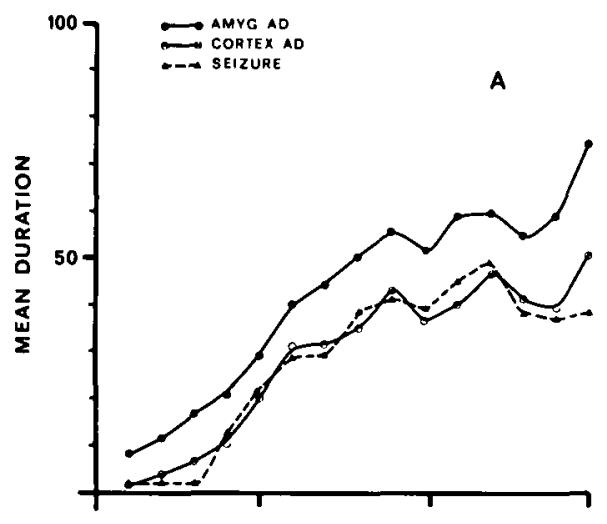

B

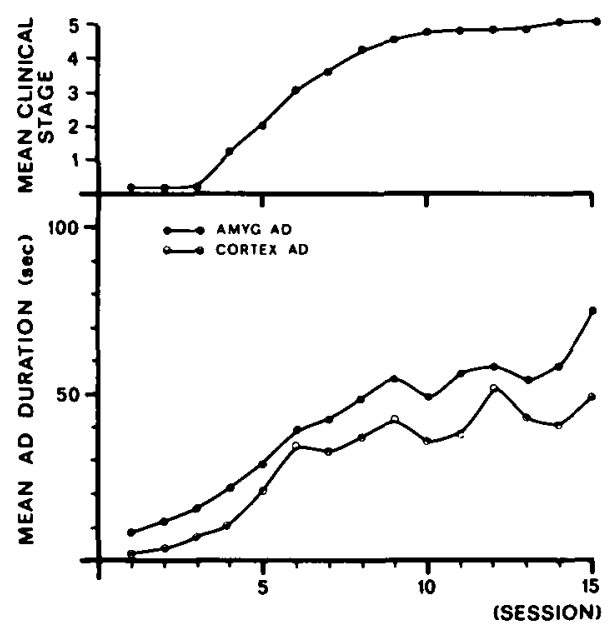

Figure I-Relation between the development of kindled amygdaloid convulsions and the duration of cortical and amygdaloid ( $A M Y G$ ) afterdischarge (AD). Note the growth of cortical $A D$ in the absence of a clinical seizure on the third trial. The classification of clinical seizures (stages 1-5) is described in the text.
Skinner's atlas (1971a)) and the posterior over area 4, with an interelectrode distance of approximately $4 \mathrm{~mm}$. Another screw driven into the frontal bone served as a ground.

\section{Procedure}

The rats received $1 \mathrm{sec}$. of electrical stimulation each day, delivered via the amygdaloid electrode in the left hemisphere. A constant current sine wave source provided the stimulation, which was delivered at an intensity of $160 \mu \mathrm{A}$. EEG was recorded bipolarly on a Grass 8-channel machine. The pattern of development of clinical manifestations was classified using a modification of the categories developed by Racine (1972): C-1, mouth and facial movements; $\mathrm{C}-2$, the above followed by head nodding; $\mathrm{C}-3$, the above followed by clonus of the contralateral forelimb; $\mathrm{C}-4$, the above followed by bilateral clonus of the forelimbs with rearing; $\mathrm{C}-5$, the above followed by loss of balance and generalized clonic jerking.

After the experiment the rats were killed with an overdose of pentobarbital, and frozen coronal sections of their brains were examined to localize the placement of the depth electrodes.

\section{RESULTS}

The development of clinical seizures was paralleled by growth in the duration of afterdischarge (AD) in amygdala and motor cortex, but the duration of the clinical response seemed to be more closely related to the duration of $\mathrm{AD}$ in motor cortex than in amygdala (Fig. 1A). The appearance of $\mathrm{AD}$ in motor cortex was not inevitably correlated with the development of clinical manifestations, however, especially during the early stages of kindling. As shown in Fig. IB, for example, the development of AD in motor cortex on the third trial was not accompanied by a similar recruitment of clinical signs. Conversely, clinical manifestations appeared in some animals before AD developed in motor cortex, as shown in part C-1 of Fig. 2a.

As kindling progressed the morphology and frequency of $\mathrm{AD}$ in motor cortex also developed. The results from a representative subject are shown in Fig. 2:

a). A very low amplitude spike discharge of about $10 \mathrm{~Hz}$ appeared from the earliest stimulations and persisted until the initial development of $\mathrm{C}-3$ seizures (Fig. 2a). The amplitude of the $A D$ progressively increased, and the discharge became clearly bilateral as $\mathrm{C}-3$ seizures developed.

b). After the development of C-3 seizures a pattern of cortical $A D$ at a frequency of $15 \mathrm{~Hz}$ appeared that was independent of amygdaloid $A D$ (Fig. 2b, 2c) and persisted throughout the appearance of $\mathrm{C}-4$ seizures. The $15-\mathrm{Hz}$ pattern was intermixed with the original $10-\mathrm{Hz} A D$, and tended to appear transiently during the midportion of an individual seizure.

c). As C-5 seizures developed, the frequency of the independent cortical spikes increased to about $20 \mathrm{~Hz}$, apparently in association with the development of a $4-8 \mathrm{~Hz}$ irregular spike and wave in the amygdala. Subsequently, multiple spike and waves appeared in amygdala and motor cortex. Repeated stimulation of the amygdala after the development of $\mathrm{C}-5$ seizures resulted in a more complicated pattern of irregular spike and waves in the cortex, in conjunction with increasingly violent seizure manifestations (e.g., repeated loss of balance, violent and sustained generalized jerking). The duration of the clinical response was reliably correlated with the duration of cortical but not amygdaloid AD in animals with well-established kindled seizures.

\section{DISCUSSION}

These results confirm Tanaka's (1972) observation that the development of kindled amygdaloid seizures is correlated with evolution in the $\mathrm{AD}$ activity recorded from the motor cortex. The appearance of independent or "reactive" (Delgado and Sevillano, 1961) AD in motor cortex during stage $C-3$ suggests that the motor cortex might be causally involved in the exacerbation and generalization of clinical manifestations during the late stages of amyg- 
daloid kindling. According to this hypothesis, other (presumably deep) structures participate in the development of clinical manifestations before C-3. It should be noted, however, that although suggestive these data are only correlative, and cannot establish a causal relation between kindling and epileptiform activity in the motor cortex. It is possible, for example, that kindling of clinical seizures and the development of independent $\mathrm{AD}$ in the motor cortex are both due to the activity of some other part of the brain, perhaps in the brainstem. In an attempt to determine whether epileptiform activity in the motor cortex is causally related to kindling, we performed an experiment in which the motor cor- tex and other cortical areas were lesioned prior to kindling.

\section{EXPERIMENT 2: METHODS}

This experiment was designed to examine the effects on amygdaloid kindling of bilateral lesions in various parts of the cerebral cortex. One group of rats received lesions in areas 4 and 6 (motor and premotor cortices), the same areas from which electrographic recordings were obtained in Experiment 1. In order to control for the cingulate damage produced by the lesions in the motor cortex, a second group of rats received lesions in the anterior cingulate cortex. In view of the recent demonstration of a direct amygdaloid projection to areas of the
C-0

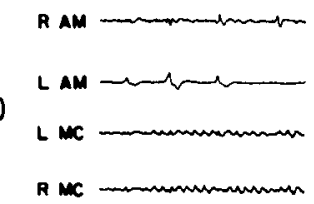

c-1

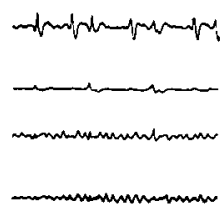

c-2
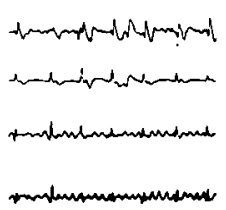

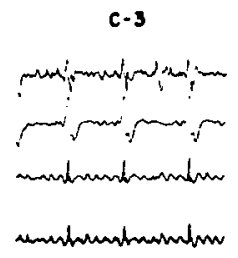

$\mathbf{3}$

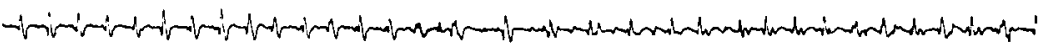

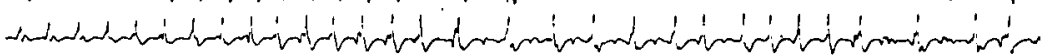

(b)

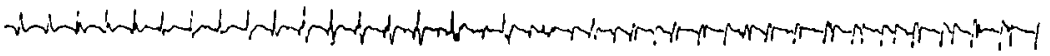

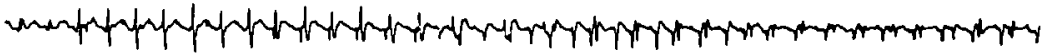

C.4

(c)

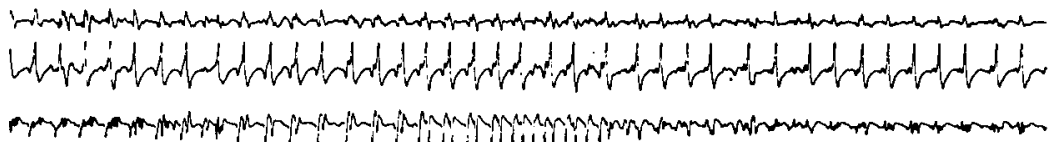

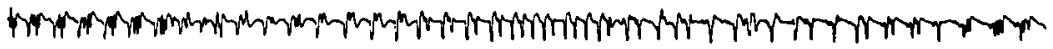

C-5

(d)

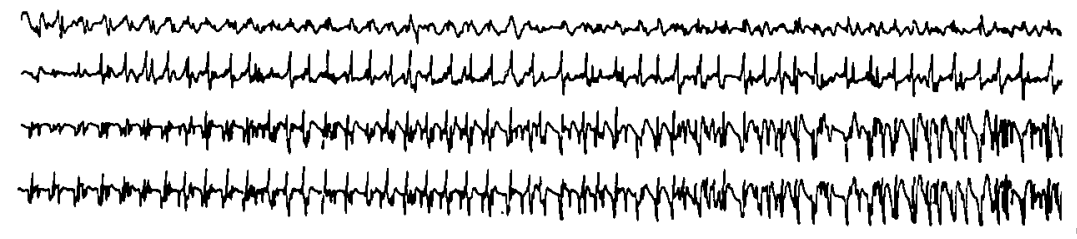

Figure 2-Electrographic records taken from a representative rat, depicting the development of cortical and amygdaloid AD during amygdaloid kindling. Stimulation was applied via the amygdaloid electrode in the left hemisphere. The classification of clinical seizures (stages $\mathrm{C}-0$ through $\mathrm{C}-5$ ) is described in the text. Abbreviations: $\mathrm{R}-\mathrm{AM}$ and L-AM, right and left amygdalae; $\mathrm{R}-\mathrm{MC}$ and $\mathrm{L}-\mathrm{MC}$, right and left motor cortices. frontal cortex (Kretteck and Price, 1974), two additional groups of rats were prepared: One group received lesions in area 10 of prefrontal cortex, the rodent homologue of prefrontal cortex in primates (Leonard, 1969); and the other group received lesions in the sulcal cortex (i.e., on the dorsal lip of the rhinal sulcus), which according to Leonard (1969) is the rodent homologue of orbitofrontal cortex. Finally, a group of rats received large lesions in posterior neocortex.

\section{Subjects and surgery.}

Six groups of male hooded rats were prepared, with $7-10$ rats in each group. The rats weighed 250 $350 \mathrm{~g}$ at the time of surgery, and were housed individually with free access to food and water. The rats in the five experimental groups received one-stage bilateral aspiration lesions of the cortex; the area to be lesioned was identified by reference to the literature (Kretteck and Price, 1974; Leonard, 1969) and with the use of the cortical maps in Skinner (1971a). The rats were anesthetized and placed in a stereotaxic apparatus, and a bone flap was removed bilaterally over the area to be lesioned. A protective strip of bone was left intact over the sinus. The dura was cut, and cortical tissue was removed by suction. When necessary Gelfoam was used to staunch excessive bleeding. In the control rats, bone flaps were removed and the dura cut, but no cortical tissue was aspirated. In the same operation bipolar amygdaloid electrodes were implanted bilaterally in all rats. The construction of the electrodes was identical to that of Experiment 1.

\section{Procedure.}

The schedule of amygdaloid stimulation began $10-14$ days after surgery. The rats were first kindled by stimulation of the left amygdala (primary site); after three C-5 seizures had been evoked, they were subjected to repeated stimulation in the right amygdala (secondary site). The present paper will report the results of kindling from the primary site only. One sec. of electrical stimulation was provided each day by a constant current $60-\mathrm{Hz}$ sine 
wave source, and was initially delivered at an intensity of $30 \mu \mathrm{A}$. If 30 $\mu \mathrm{A}$ was not sufficient to evoke AD in the amygdala, the current was raised in successive sessions by 10 $\mu$ A steps until $\mathrm{AD}$ was evoked. The lowest intensity of stimulation sufficient to evoke amygdaloid AD was arbitrarily considered the threshold, and all rats were kindled at the threshold intensity.

At the end of the experiment the rats were killed with an overdose of pentobarbital. After intracardiac perfusion with physiological saline and formalin, their brains were removed. Drawings and photographs were made of the cortical lesions when appropriate, and then frozen coronal sections $40 \mu \mathrm{m}$ thick were taken through the areas of the cortical lesions and the tracks of the amygdaloid electrodes.

\section{Lesions.}

\section{RESULTS}

The extent of the lesions in the five experimental groups is indicated in Fig. 3.

Prefrontal group (Fig. 3A): The prefrontal lesions were large and bilaterally symmetrical, and typically involved substantial damage to area 10 (prefrontal) and area 6 (premotor). In some rats there was minor involvement of areas. 23 and 24 (anterior cingulate) or area 4 (motor). Damage to the underlying corpus callosum ranged from partial to total transection in different animals, but in this and the other groups there was no relation between be- havioral effects and damage to the white matter.

Motor cortex group (Fig. 3B): The lesions typically involved all of areas 4 and 23 bilaterally, most of area 6 , and the anterior part of area $29 \mathrm{c}$ (posterior cingulate). The underlying corpus callosum was transected in some rats but totally spared in others.

Cingulate group (Fig. 3C): The lesions destroyed all of areas 23 and 24 (anterior cingulate), parts of the medial borders of areas 10,6 and 4, and occasionally intruded into area $29 \mathrm{c}$. The cingulate lesions extended as far rostrally as the frontal lesions, and farther caudally. Damage to the white matter ranged from total transection to total sparing of the corpus callosum.

Posterior group (Fig. 3D): The lesions were large and bilaterally symmetrical. They destroyed area 17 (striate) and invaded areas 18, $18 \mathrm{a}$, and adjacent cortex. The amount of cortical tissue destroyed was comparable to that produced by the prefrontal lesions. Subcortical damage involved the superior colliculus and occasionally the dorsal aspects of the central gray.

Orbital group (Fig. 3E): The lesions were located bilaterally in the sulcal cortex, on the dorsal lip of the rhinal sulcus (Leonard, 1969), and extended caudally into the perirhinal cortex. There was a tendency for the lesions to be larger on the right side, where they extended medially and occasionally intruded into the ex-
TABLE 1

Number of rats in each group displaying amygdaloid afterdischarge at each intensity

\begin{tabular}{l|c|c|c}
\hline \multicolumn{4}{|c}{ of stimulation } \\
\hline Group & \multicolumn{3}{|c}{$\begin{array}{c}\text { Intensity of electrical } \\
\text { stimulation }\end{array}$} \\
\hline & $30 \mu \mathrm{A}$ & $40 \mu \mathrm{A}$ & $50 \mu \mathrm{A}$ \\
\hline Control & .3 & 6 & 0 \\
Prefrontal & 7 & 1 & 0 \\
Motor & 10 & 0 & 0 \\
Cingulate & 3 & 5 & 1 \\
Posterior & 5 & 3 & 0 \\
Orbital & 7 & 0 & 0 \\
\hline
\end{tabular}

TABLE 2

Number of rats in each group omitting stages of amygdaloid seizure development

\begin{tabular}{l|c|c|c|c|c}
\hline Group & \multicolumn{5}{|c}{ Stage of clinical seizure } \\
\hline & C-0 & C-1 & C-2 & C-3 & C-4 \\
\hline $\begin{array}{c}\text { Control } \\
(n=9)\end{array}$ & 5 & 1 & 7 & 7 & 3 \\
$\begin{array}{c}\text { Prefrontal } \\
(n=8)\end{array}$ & 4 & 0 & 3 & 0 & 0 \\
$\begin{array}{c}\text { Motor } \\
(n=10)\end{array}$ & 0 & 1 & 0 & 3 & 2 \\
$\begin{array}{c}\text { Cingulate } \\
(n=9)\end{array}$ & 0 & 3 & 1 & 1 & 0 \\
$\begin{array}{c}\text { Posterior } \\
(n=8)\end{array}$ & 0 & 0 & 2 & 2 & 3 \\
$\begin{array}{c}\text { Orbital } \\
(n=7)\end{array}$ & 0 & 3 & 2 & 0 & 0 \\
\hline
\end{tabular}

treme lateral aspects of the anterior caudate-putamen.

\section{Kindling.}

Fig. 4 shows the effects of the lesions on the rate at which the rats developed kindled amygdaloid convulsions. It is evident that only the

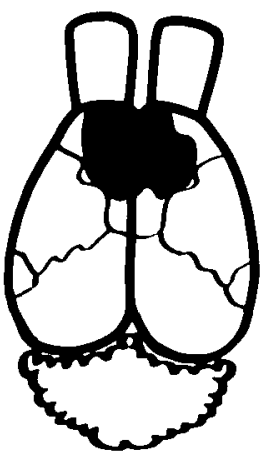

PREFRONTAL
B

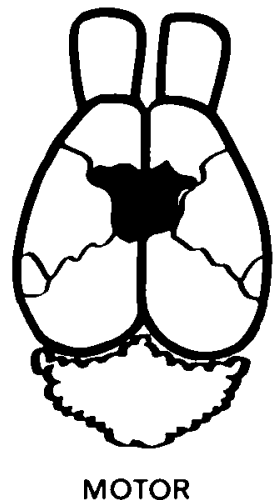

C

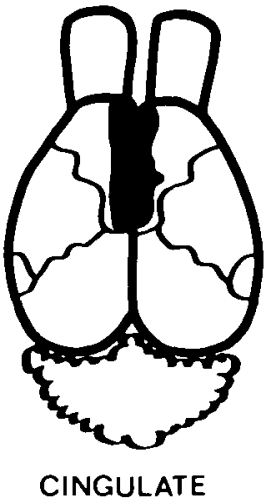

D

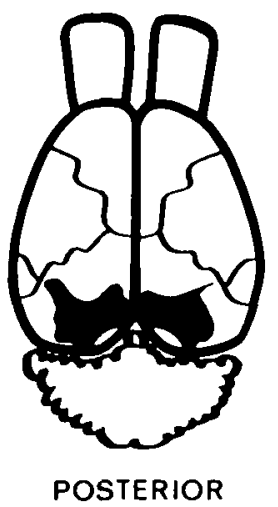

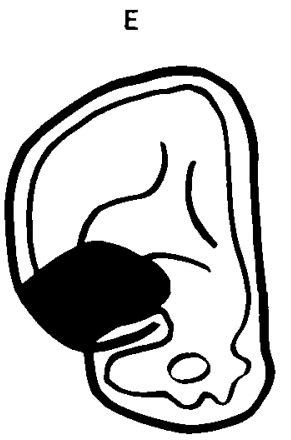

ORBITAL

Figure 3-Schematic drawings of the average areas of cortical destruction in each of the experimental groups. Fig. 3A-3D are redrawn from the cortical maps published in Skinner (1971a). 
rats with prefrontal and orbital lesions required more stimulations than controls to develop the "final" (C-5) stage of amygdaloid seizures. The mean number of stimulations required to evoke the first C-5 seizure in each group was: controls, 11.6 ; cingulate, 11.9 ; posterior, 13.0 ; motor, 13.3; prefrontal, 20.6; and orbital, 23.4. Only the prefrontal and orbital groups differed significantly from the controls (each $p<0.001$ ).

Fig. 5 provides a more detailed analysis of the data; it depicts the mean number of sessions each group spent in each stage of seizure development. This figure indicates that the major effect of the prefrontal and orbital lesions was to retard the rate at which the rats progressed beyond stage C-4. It is evident, therefore, that the frontal-lesioned rats were kindling relatively normally up to stage C-4, in which stage they perseverated significantly longer than the other rats. The other cortical lesions were not without effect, however, as suggested by two observations. First, all lesioned groups but the cingulate group tended to have initial thresholds for amygdaloid AD lower than that of the controls (Table 1). Second, as shown in Table 2, control but not lesioned rats tended to omit certain stages of seizure development during kindling. For example, the majority of controls omitted stages $\mathrm{C}-0$ and especially $\mathrm{C}-2$ and $\mathrm{C}-3$; in contrast, only a minority of lesioned rats in any group tended to omit stages of seizure development, and in many cases there was no incidence of omitting a given stage by a given lesioned group. In a sense, therefore, irrespective of locus the cortical lesions tended to increase the sequential predictability of amygdaloid kindling.

\section{DISCUSSION}

These results indicate that certain areas of the frontal cortex participate in amygdaloid kindling. Bilateral lesions of prefrontal cortex and orbital (sulcal) cortex significantly retarded the rate at which rats developed the "final" C-5 stage of kindled amygdaloid seizures. In contrast, lesions of the posterior neocortex, anterior cingulate cortex, and

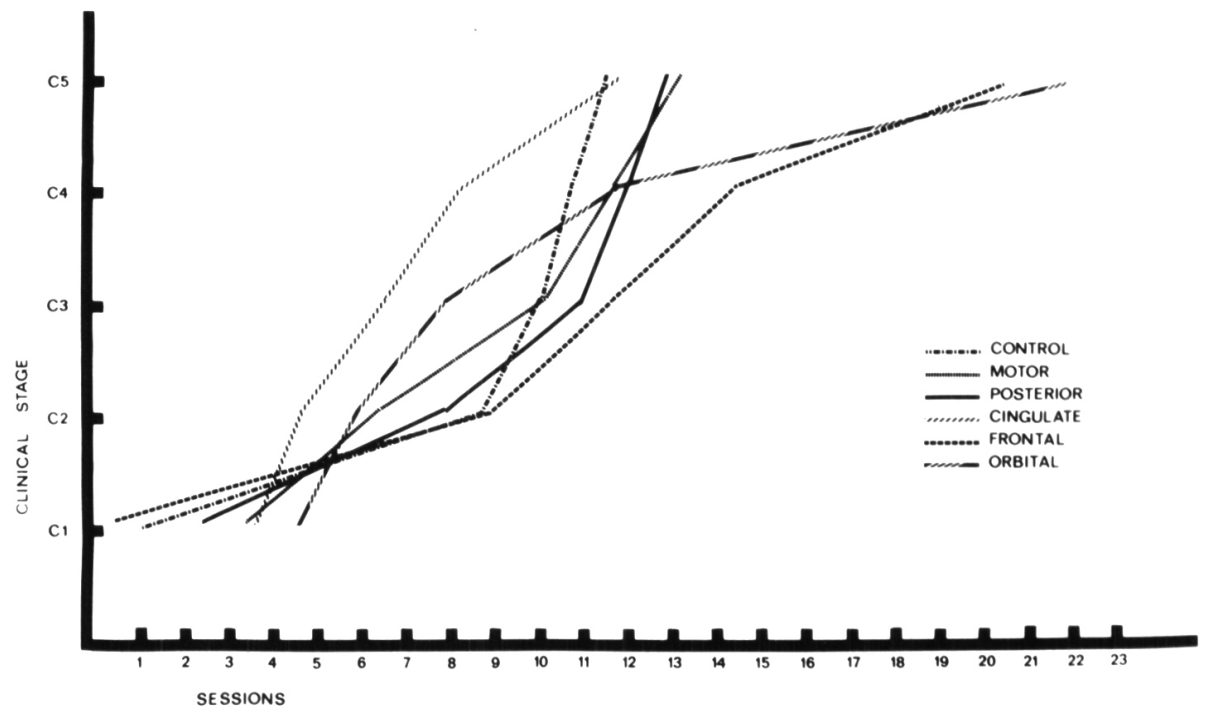

Figure 4-Effects of cortical lesions on the mean rate at which rats developed each stage of kindled amygdaloid seizures.

the motor cortex did not affect the rate of amygdaloid kindling, suggesting that these cortical areas are not essential for the development of seizures provoked by subcortical stimulation. The unexpected failure of lesions of the motor cortex (areas 4 and 6) to retard kindling indicates that electrophysiological evidence of motor cortical participation in kindling (Tanaka, 1972; and Experiment 1 of the present report) must be interpreted with caution in the absence of corroborating evidence obtained by converging operations. The lesion data cannot of course rule out the possibility that the motor cortex plays some role in amygdaloid kindling, as suggested by the results obtained in Experiment 1. Rather, the ineffectiveness of lesions of the motor cortex indicates that this area is not critically involved in kindling, although it may play some role in the intact animal. Delgado and Sevillano (1961) noted a similar lack of effect of motor cortical lesions on the clinical manifestations produced by repeated electrical stimulation of the hippocampus in cats.

The detailed analysis of the pattern of kindling shown in Fig. 5 indi-

Figure 5-Mean number of sessions spent by each group of rats in each stage of amygdaloid kindling. The inverted triangles $(\nabla)$ indicate that the group differs from the controls at the 0.01 level of significance.

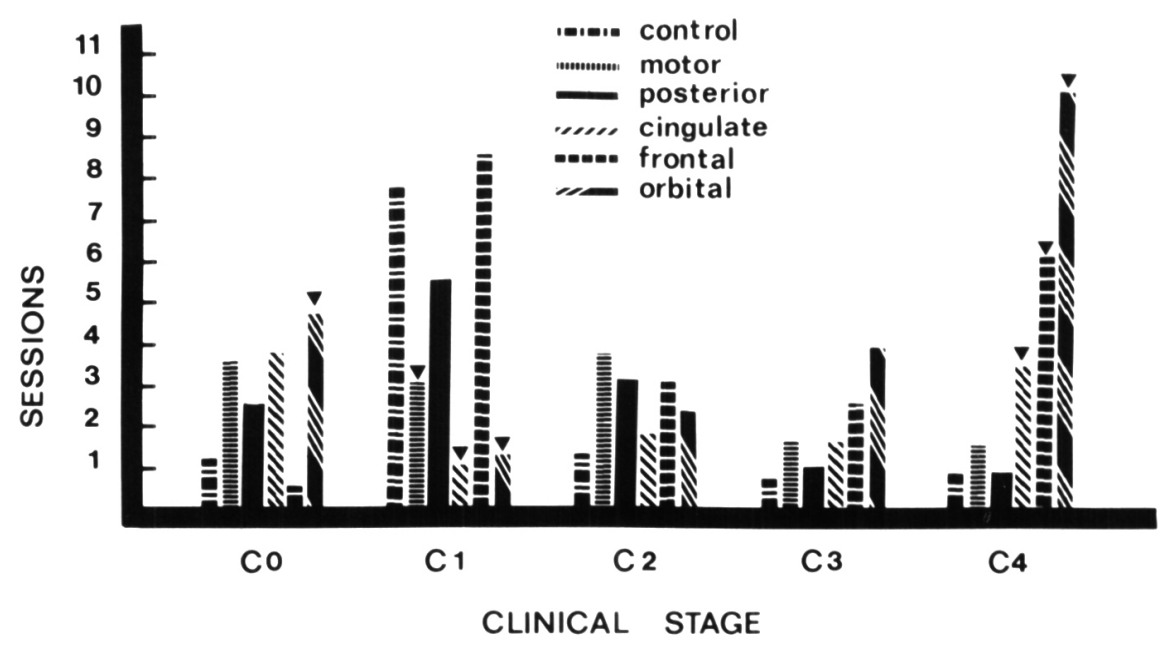


cates that the primary effect of prefrontal and orbital lesions is to delay the progression of the clinical response from stage $\mathrm{C}-4$ to stage $\mathrm{C}-5$, the "final" stage of violent generalized convulsions. Thus it appears that areas of frontal cortex participate in the late generalization of amygdaloid seizures, whereas presumably other structures are actively involved in the development of the earlier stages of kindling. Furthermore, the effects of the prefrontal and orbital lesions are not restricted to the development of seizures, as indicated by the results we are currently obtaining in a replication of the results reported here: Even after finally developing C-5 seizures, rats with restricted prefrontal or orbital lesions repeatedly regress to earlier stages of seizure development, a phenomenon never observed in sham-lesioned control rats (Corcoran, Urstad, and Wada, unpublished). For example, lesioned rats may eventually develop an isolated $\mathrm{C}-5$ convulsion, but on subsequent sessions regress to $\mathrm{C}-4$ or $\mathrm{C}-3$ manifestations, which usually progress back to the fullblown C-5 manifestations in some later session. Thus even the expression of established amygdaloid seizures is disrupted in rats bearing orbital or prefrontal lesions. Presumably these areas of frontal cortex in some way reinforce or sustain the convulsive readiness of the "kindling circuits" established elsewhere in the brain. However, we should remember that kindling up to and eventually including C-5 manifestations occurs even in the rats with prefrontal or orbital lesions, which indicates that the integrity of these areas of frontal cortex is not essential for kindling to occur.

Our emphasis on the participation of prefrontal and orbital cortices in amygdaloid kindling in rats seems reasonable in view of the known anatomy of the regions and their relations with the amygdala. For example, a projection from the amygdala to the dorsomedial (DM) nucleus of the thalamus has recently been identified in the rat with the axoplasmic tracing technique (Kretteck and Price, 1974), and the cor- ticopetal projection from DM thalamus is well known (Domesick, 1972; Kretteck and Price, 1974; Leonard, 1969, 1972). Kretteck and Price (1974) have also described a direct (presumably monosynaptic) amygdalofugal projection to prefrontal and orbital cortices in rats, which might be an additional route by which the amygdala can recruit epileptiform activity in the frontal lobe. On the efferent side, the projections of the frontal cortex to widespread telencephalic, diencephalic, and mesencephalic areas (Leonard, 1969; Nauta, 1971) are also consistent with its proposed role in the elaboration and generalization of amygdaloid seizures. Indeed, in view of the emphasis that has been placed on the possible participation of the mesencephalic reticular formation in kindling (McCaughran, Corcoran, and Wada, 1975; McIntyre, 1975; Wada and Sato, 1974, 1975), it is of interest that Leonard (1969) has described a prominent projection to parts of the mesencephalon from both the prefrontal and orbital cortices in rats.

Aside from the anatomy, there are other indications that areas of the frontal lobe may participate in epileptiform activity. For example, the orbital cortex is known to be part of a thalamocortical system that regulates several forms of synchronous activity (Skinner, 1971b; Skinner and Lindsley, 1967; Velasco, Skinner, Asaro \& Lindsley, 1968), and epilepsy can be viewed as a form of hypersynchronous activity. By stimulating frontal lobe in epileptic patients with primary generalized seizures, Bancaud et al. (1974) were able to evoke seizures identical to those spontaneously emitted by the patients. These results led Bancaud et al. to emphasize the preponderant role played by the frontal lobe in the generalization of epileptic attacks.

A final word may be appropriate concerning possible species differences in the functions of the frontal lobe in amygdaloid kindling. Wake and Wada (1975) have cited evidence indicating that the mechanisms of orbitofrontal kindling overlap those of amygdaloid kindling in cats, which is consonant with the findings reported in the present paper. Seizures kindled by repeated electrical stimulation of prefrontal cortex differ markedly from amygdaloid seizures in both cats (Wake and Wada, 1975) and baboons (Wada, Osawa, and Mizoguchi, 1975) however, suggesting that in those species the prefrontal cortex does not participate in amygdaloid kindling. This conclusion is at variance with our interpretation of the results obtained with rats in the present experiments, and several explanations for this discrepancy can be considered. First, the anatomy of the rat's prefrontal cortex is similar to but not identical with that of other species (Leonard, 1969, 1972), and it is possible that the functions of the prefrontal cortex also vary in the difference species. There may be a genuine species difference in the functioning of the prefrontal cortex that is measurable in the amygdaloid kindling paradigm. Second, the positive evidence linking the prefrontal cortex to amygdaloid kindling in rats was based on the effects of prefrontal lesions, whereas the negative evidence obtained in cats and baboons was based on the effects of electrical stimulation delivered to the prefrontal cortex. The different results might be accounted for by differences in the procedures of the experiments. It is possible, for example, that the effects obtained with cortical lesions were due to the destruction of an anatomically restricted group of cortical neurons, and that, due to the relatively discrete and localized nature of the field of current, the electrical stimulation used in prefrontal kindling failed to spread to and activate the critical neurons. Alternatively, amygdaloid kindling may be due to the activation of a variety of amygdaloid efferents, including those to the prefrontal cortex. Stimulation of the prefrontal cortex, on the other hand, presumably would not activate the same total profile of neural systems activated by amygdaloid stimulation. Thus, the prefrontal cortex might participate in amygdaloid kindling even though repeated cortical stimulation does not result in the development of amygdaloid-like seizures. Whatever the correct explanation of these dis- 
crepancies, perhaps the only safe conclusion that should be drawn at present is that further experiments are required to unravel the role of the frontal lobe in amygdaloid kindling.

\section{DISCUSSION}

Dr. Burnham: A couple of comments relative to Corcoran's material. I want to quibble again about the exact analogue of what Kreig designates as area 10. I think that we have to be very careful about this. He calls it prefrontal but I don't know that it relates to what we call prefrontal tissue in a human. Once again, Woolsey's maps, which are somewhat hard to interpret, seem to place that in the primary motor area, somewhere around the body area; so that it may be essentially the motor cortex even though Kreig felt that it didn't look very much like motor cortex. That is something to be looked into. I wonder, too, about connections from the amygdala to cortex through the dorsal thalamus. Has that been shown in the rat? Dr. Corcoran: First, I believe that it is standard to consider area 10 prefrontal cortex in rat, Woolsey notwithstanding; certainly, the degeneration seen after the lesions of this area in rats is similar to that after prefrontal lesions in primates. So I am only going by what other people say, and I am not really prepared to defend their work. With regard to your second question, Kretteck and Price have shown a connection from amygdala to dorsomedial thalamus in rat, using the axoplasmic transport technique; I believe that neuroanatomists have failed to see this amygdalofugal projection in the rat when they used degeneration stains. Kretteck and Price verified the well known projection from DM thalamus to frontal cortex, but they have also described a direct amygdalofrontal projection that has not previously been observed with traditional anatomical techniques. So I believe that there are several possible routes by which the amygdala can communicate with the frontal cortex in rats. Dr. McIntyre: Mike, in terms of your convulsion proper, did you make any notes on severity? Like the intact convulsion as you mentioned is delayed in evolution but what do they look like? $\mathrm{Dr}$. Corcoran: Yes, we did look at that. I don't have those data completely analyzed yet, but it looks as if even once they are kindled, these frontal-lesioned animals are still different from controls in the sense that controls will, within a given seizure, develop into the $C 5$ stage of violent thrashing about and will be in that for a while and then they will shut off, at least they tend to in our situation. On the other hand, the lesioned animals will build up and spend very little time in the final stages of C4-C5; even though they reach it, they don't spend much time in it and they regress to lower stages of seizure activity until they sort of peter out after a while. It is a less sharp termination of the seizure. I don't recall if this happens in animals with cortex lesions. $D r$. Mcintyre: I made some lesions like this and they include what you are describing as motor cortex as well as frontal cortex and the con- vulsions there are very markedly attenuated in the bilateral animals. What we did, was to look at the transfer-interference effects by making unilateral lesions ipsilateral and contralateral to the primary site to look at the interference. With unilateral aspirations, we got unilateral convulsions of the kind described with transections with an animal sitting up and holding one forepaw and having its convulsions with the contralateral. What was interesting was that they had these unilateral convulsions independently. It didn't matter what focus you triggered them from. Dr. Burnham: Did the animals go through the whole of Racine's 5 stages? Dr. McIntyre: The bilateral cortex animals did not show the rearing and falling. The unilateral cortex animals do show all 5 stages. Dr. Burnham: When you had your big posterior cortical removals, did they have any effect on the seizure at all? Sometimes just removing large areas of cortex somehow seems to weaken the animal. Dr. Corcoran: No, there was no effect at all. Dr. Pinel: It may be worthwhile looking at Mason \& Cooper's study. I believe that they included some lesioned animals in their metrazol kindling although 1 can't recall, it seemed to potentiate the kindling, I think. I would strongly argue that there is no such thing as an afterdischarge $50 \%$ of the time. Just about everybody, including myself, has used this term while giving papers, but we find that every time you stimulate an animal you change that threshold; thus it seems impossible to ever find it and you can bring it down or up or you can move it all over the place. It is a very fleeting kind of thing and one has to talk about it with a bit of conservatism and always to very precisely specify the methods that one has used in determining it. Dr. Corcoran: Yes, I agree with that. Of course, threshold is a statistical concept and it doesn't really reflect the realities of the nervous system. I believe that it is a labile thing. Perhaps it would be better to say that we used a suprathreshold level of current, without being any more specific. We could also call it the "X" factor: it doesn't matter what we label it, although I must agree that it doesn't really measure an actual threshold. It was more for convenience that I called it that. $D r$. McIntyre: Perhaps in the context of threshold, I think that you will find that there are terrific differences in terms of how long you had your current on. With 5 seconds, I find all kinds of animals with threshold like 4 or 5 microamps; so when you talk about 30 microamps and the difference between 30 microamps and 37 microamps. How significant is it? Dr. Corcoran: Well. I can only say that those differences though small were statistically significant. Dr. Penry: Dr. Adler used chronic lesions in rats to develop a model for evaluating antiepileptic drugs. He found that the ablation of various cortical areas lowered the threshold to chemically induced seizures. How do you reconcile your findings with Adler's ablation model for testing anticonvulsant drugs? Dr. Corcoran: Yes, I recall that Adler found a lowered threshold to fluorthyl-induced seizures following either frontal or posterior cortical lesions. But I don't remember the details of his experiments well enough to comment further at this time. Dr. Wada: In order to make a somewhat confusing frontal picture more complicated, I would like to ask Dr. Cain to briefly comment on our finding of olfactory bulbectomy and kindling. Dr. Cain: Dr. Corcoran and I have obtained some preliminary evidence on the effect of olfactory system ablations on amygdaloid kindled seizures. Based on prior work by Japanese workers showing a raised threshold and reduced intensity of seizures induced by various means in olfactory bulbectomized mice, we used bulbectomized rats with amygdala electrodes in a standard kindling procedure. A second group with larger olfactory system ablations including the anterior olfactory nucleus and surrounding structures, as well as inferior frontal cortex in most cases, was also included. Animals with ablations restricted to the olfactory bulbs were unaffected, while those with the large ablations were facilitated in their rate of kindling. This effect is present from the first stimulation since initial afterdischarge duration in this group is double that of the control group. It appears there is a system suppressing amygdala afterdischarge in the vicinity of the anterior olfactory nucleus or inferior frontal cortex. I understand from Dr. Racine that work done in his laboratory in collaboration with Dr. George Paxinos has demonstrated a similar facilitation of amygdaloid kindling after knife cuts of the stria terminalis. Since portions of this tract project from the amygdala to the anterior olfactory nucleus, it is likely that we have interrupted the same system in each case. Dr. Wada: We have been following one of the prefrontal kindling baboons for some time now. Probably Dr. Mizoguchi can tell us briefly what he has found so far regarding this longitudinal follow-up. $D r$. Mizoguchi: We have attempted re-kindling at the primary prefrontal cortical site seven months following the termination of the previous brain stimulation. Stimulation of the primary site at the established GST which was $300 \mu$ it was totally ineffective. However. step-wise elevation of stimulus intensity to $600 \mu \mathrm{a}$, which is $100 \mu$ a less than the original $A D$ threshold, produced a localized $A D$ associated with the Stage 1 clinical seizure manifestation. Daily electrical stimulation at this intensity produced a progressive seizure recruitment developing the final Stage 5 seizure on the 85 th stimulation. This would mean that this animal progressed to this final stage at a speed roughly five times that of the initial kindling (85 as against 389 ). GST examination showed it to be $250 \mu$ a as against the initial GST of $300 \mu$ a. Although the rate of development was much faster during rekindling, the time spent for each successive clinical seizure stage was roughly proportional to that of the original kindling. GST were somewhat lower than the initial kindling in addition to markedly accelerated rate of kindling during re-kindling. All this suggested that subtle but permanent reorganization of brain function must have taken place following the initial kindling. Dr. Wada: I think that the regression of established prefrontal kindling suggests a possibility that such an induced process of brain reorganization might dissi- 
pate with time. This reminds us of an intriguing parallel to the mechanism of spontaneous remission which occurs in human epilepsy. Are there any further questions or discussion on the frontal lobe and kindling? Perfect! This is exactly what I had hoped. Now, we will have slightly more than one hour rather than thirty minutes for general discussion. I would like to call upon Dr. Daly to open our final discussion.

\section{REFERENCES}

BANCAUD, J., TALAIRACH, J., MOREL, P. BRESSON, M., BONIS, A., GEIER, S., HEMON, E. and BUSER, P. (1974). "Generalized" epileptic seizures elicited by electrical stimulation of the frontal lobe in man. Electroencephalography and Clinical Neurophysiology, 37, 275-282.

DELGADO, J. M. R. and SEVILLANO, M. (1961). Evolution of repeated hippocampal seizures in the cat. Electroencephalography and Clinical Neurophysiology, 13, 722-733.

DOMESICK, V. B. (1972). Thalamic relationships of the medial cortex in the rat. Brain, Behavior and Evolution, 6, 457-483.

KRETTECK, J. E. and PRICE, J. L. (1974). $A$ direct input from the amygdala to the thalamus and the cerebral cortex. Brain Research, 67, 1969-174.
LEONARD, C. M. (1969). The prefrontal cortex of the rat. I. Cortical projections of the mediodorsal nucleus. II. Efferent connections. Brain Research, 12, 321-343.

LEONARD, C. M. (1972). The connections of the dorsomedial nuclei. Brain, Behavior and Evolution, 6, 524-541.

McCAUGHRAN, J. A., CORCORAN, M. E. and WADA, J. A. (1975). Development of kindled amygdaloid seizures in split-brain rats. Submitted for publication.

McINTYRE, D. C. (1975). Split-brain rat: transfer and interference of kindled amygdala convulsions. Canadian Journal of Neurological Sciences, 2. This issue.

NAUTA, W. J. H. (1971). The problem of the frontal lobe: a reinterpretation. Journal of Psychiatric Research, 8, 167-187.

RACINE, R. J. (1972). Modification of seizure activity by electrical stimulation. II. Motor seizure. Electroencephalography and Clinical Neurophysiology, 32, 281-294.

SKINNER, J. E. (1971a). Neuroscience: a laboratory manual. Philadelphia: W. B. Saunders.

SKINNER, J. E. (1971b). Abolition of several forms of cortical synchronization during blockade in the inferior thalamic peduncle. Electroencephalography and Clinical Neurophysiology, 31, 211-221.

SKINNER, J. E. and LINDSLEY, D. B. (1967). Electrophysiological and behavioral effects of blockade of the nonspecific thalamo-cortical system. Brain Research, 6, 95-118.

TANAKA, A. (1972). Progressive changes of behavioral and electroencephalographic responses to daily amygdaloid stimulations in rabbits. Fukuoka Medical Journal, 63, 152-164.

VELASCO, M., SKINNER, J. E. ASARO, K. D. and LINDSLEY, D. B. (1968). Thalamo-cortical systems regulating spindle bursts and recruiting responses. I. Effect of cortical ablations. Electroencephalography and Clinical Neurophysiology, $25,463-470$.

WADA, J. A., OSAWA, T. and MIZOGUCHI, T. (1975). Recurrent spontaneous seizure state induced by prefrontal kindling in Sengalese baboons, Papio papio. Canadian Journal of Neurological Sciences, 2. This issue.

WADA, J. A. and SATO, M. (1974). The generalized convulsive seizure state induced by daily electrical stimulation of the amygdala in cats: correlative electrographic and behavioral features. Neurology, 24, 565-574.

WADA, J. A. and SATO, M. (1975). Effects of unilateral lesion in the midbrain reticular formation upon kindled amygdaloid convulsion in cats. Epilepsia, in press.

WAKE, A. and WADA, J. A. (1975). Frontal lobe and kindling in the cat. Canadian Journal of Neurological Sciences, 2. This issue. 